4 Vasconcelos-Moreno MP, Fries GR, Gubert C, dos Santos BTMQ, Fijtman A, Sartori J, et al. Telomere length, oxidative stress, inflammation and BDNF levels in siblings of patients with bipolar disorder: implications for accelerated cellular aging. Int J Neuropsychopharmacol. 2017;20:445-54.

5 Czepielewski LS, Massuda R, Panizzutti B, da Rosa ED, de Lucena $D$, Macêdo D, et al. Telomere length in subjects with schizophrenia, their unaffected siblings and healthy controls: evidence of accelerated aging. Schizophr Res. 2016;174:39-42.

\section{BDNF Val66Met polymorphism and memory performance in older adults: the Met carrier effect is more complex than previously thought}

Rev. Bras. Psiquiatr. 2017;39:276

doi:10.1590/1516-4446-2017-2240

Brain-derived neurotrophic factor (BDNF) is an important nerve growth factor linked with development and neural plasticity. The Val66Met polymorphism in the BDNF gene has been associated with a significant impact on episodic memory in adults. Azeredo et al. ${ }^{1}$ investigated effects of the BDNF Val66Met polymorphism on memory performance. Their conclusion was that, in a sample of elderly adults, BDNF Met allele carriers had impaired episodic memory performance as compared to Val/Val homozygotes. ${ }^{1}$ However, conflicting evidence to this report exists, and the correlation between memory and Met allele carrier status is quite complex. One previous report focusing on older adults suggested that the BDNF Met allele is associated with higher memory performance, ${ }^{2}$ whereas other studies found no effect of BDNF Val66Met variant on memory in older ${ }^{3}$ or young adults. ${ }^{4}$ It is important to note that the effects of the Val66Met polymorphism are due to modification of BDNF synthesis. Azeredo et al. measured BDNF genotype, but not BDNF concentrations. Interestingly, Val66Met polymorphism has been shown to be associated with increased BDNF levels by Zhang et al., ${ }^{5}$ vs. the BDNF reduction presumed by Azeredo et al., where aging-related memory decline is possibly explained by reduced neurotrophin synthesis. Another limitation of this study was the failure to exclude psychiatric patients. ${ }^{1}$ The BDNF increase noted in the study by Zhang et al. was demonstrated in patients with posttraumatic stress disorder, a condition known to have significant impact on memory.

In conclusion, we believe further research into the impact of $B D N F$ genotype on memory should include measurement of BDNF levels as well as psychiatric screening for conditions likely to impact memory function.

Eugene Lipov, Kenneth Candido Department of Anesthesiology, Advocate Illinois Masonic Medical Center, Chicago, IL, USA

Submitted Jan 26 2017, accepted Apr 162017.

\section{Disclosure}

The authors report no conflicts of interest.

\section{References}

1 Azeredo LA, De Nardi T, Levandowski ML, Tractenberg SG, KommersMolina J, Wieck A, et al. The brain-derived neurotrophic factor (BDNF) gene Val66Met polymorphism affects memory performance in older adults. Rev Bras Psiquiatr. 2017;39:90-4.

2 Gajewski PD, Hengstler JG, Golka K, Falkenstein M, Beste C. The Met-allele of the BDNF Val66Met polymorphism enhances task switching in elderly. Neurobiol Aging. 2011;32:2327.e7-19.

3 Benjamin S, McQuoid DR, Potter GG, Payne ME, MacFall JR, Steffens DC, et al. The brain-derived neurotrophic factor Val66Met polymorphism, hippocampal volume, and cognitive function in geriatric depression. Am J Geriatr Psychiatry. 2010;18:323-31.

4 Gong P, Zheng A, Chen D, Ge W, Lv C, Zhang K, et al. Effect of BDNF Val66Met polymorphism on digital working memory and spatial localization in a healthy Chinese Han population. J Mol Neurosci. 2009;38:250-6.

5 Zhang L, Li XX, Hu XZ. Post-traumatic stress disorder risk and brainderived neurotrophic factor Val66Met. World J Psychiatry. 2016;6:1-6.

\section{BDNF Val66Met polymorphism and memory performance in older adults: the Met carrier effect is more complex than previously thought: Authors' reply}

Rev. Bras. Psiquiatr. 2017;39:276-277

doi:10.1590/1516-4446-2017-3904

Genetic association studies have presented inconsistent findings regarding the effects of the functional BDNF Val66Met polymorphism and cognitive function in healthy subjects and psychiatric patients, with heterogeneity in effect sizes across studies. ${ }^{1-4}$ As these candidate gene studies have employed relatively small samples, it is difficult to interpret discrepant findings, which are the norm in genetic association research. By aggregating data across studies, meta-analyses provide a systematic method of evaluating such discrepant findings, as regarding the association between BDNF Val66Met polymorphism and memory function. In this context, a recently published meta-analysis estimated the effect of the BDNF Val66Met polymorphism on declarative memory tasks in 5,922 subjects, as well as on hippocampal grey matter volume in 2,985 subjects and on task-related change in hippocampal response measured by functional magnetic resonance imaging (fMRI) in 362 subjects. ${ }^{5}$ The authors of this metaanalysis found evidence that declarative memory performance, hippocampal volume, and hippocampal activation are all reduced in BDNF Met allele carriers in comparison to $\mathrm{Val} / \mathrm{Val}$ homozygotes. In our study, we examined the effect of the BDNF Val66Met polymorphism on declarative memory performance in a sample of 87 older adults recruited by convenience among community-based elders in Porto Alegre, Brazil. Our analysis yielded further evidence on the genetic contribution of the BDNF Val66Met polymorphism in memory performance, demonstrating that $B D N F$ Met allele carriers had lower delayed verbal recall and a decline in memory retention as compared to $\mathrm{Val} / \mathrm{Val}$ homozygotes. Although our findings provided additional evidence of an 